\title{
URS Konusunda Teknolojik Gelişmeler
}

\author{
Selahattin Bedir ${ }^{1}$
}

1Sağlık Bilimleri Üniversitesi, Gülhane Tıp Fakültesi, Üroloji Anabilim Dalı, Ankara

Giriş

G ünlük üroloji pratiğimizde üriner sistem taş hastalığ Jönemli bir yer tutmaktadır. Özellikle Türkiye gibi taş kuşağında yer alan ülkelerde bu hastalık grubu daha cok önem arz etmektedir. Üriner sistem taş hastalıklarının tedavisinde son yıllarda büyük gelişmeler kaydedilmiştir. Geçmiş yıllarda açık taş cerrahileri önemli sayıda yapılırken, 1980'li yıllarda vücut dışından ses dalgaları ile taş kırma (ESWL) cihazları, üriner sistem taş hastalığının tedavisindeki yerini almıştır. Son yıllarda ise üreterorenoskop (URS)'ların geliştirilmesiyle üriner sistem taş hastalığının tedavisi dramatik bir şekilde değişmiştir. Açık taş ameliyatları günümüzde yok denecek kadar az sayıda yapılırken, perkütan nefrolitotomi ameliyatları ürolithiazis tedavisinde en invazif yöntem olarak kabul edilmeye başlanmıştır (1). Bunun sebepleri arasında; endoskopların yapısındaki değişiklikler, özellikle bükülebilir yapıdaki URS'lerin geliştirilmesi, lazer teknolojisindeki gelişmeler ve kullanılan aksesuar malzemelerdeki yenilikler sayılabilir.

URS tedavisi; ilk olarak üreter taşları ve küçük böbrek taşlarının tedavisinde ESWL'ye alternatif olarak kabul edilmekteydi $(2,3)$. Günümüzde ise URS'nin büyük böbrek taşlarında ESWL ve perkütan nefrolitotomi (PNL)'ye eşit hatta üstün olduğunu gösteren çalışmalar mevcuttur (4). Son yıllarda endoskopların tasarımında ve dayanıklıklarındaki teknolojik gelişmeler ile kullanılan aksesuarlardaki yenilikler, URS konusunda devrim yaratmıştır.

\section{Rijit URS'lerde Teknolojik Gelişim}

Üreteroskopi işlemi ilk kez Hugh Hampton Young tarafından 1912 yılında posterior üretral valvli bir çocukta uygulanmıştır. Ancak üreteroskop kullanılarak yapılan ilk planlı URS işlemi 1980 yılında Enrique Perez Castro tarafından gerçekleştirilmiştir (5). Başlangıçta en ince yerinde $13 \mathrm{~F}$ kalınlık olan URS'ler kullanılmıştır. Bu cihazların kullanıldığ 1 yıllarda üreter orifisinin standart olarak dilate edilmesi gerekiyordu. Günümüzde ise rijit URS'lerin kalibreleri 7.5F'e kadar düşürülmüştür. Bu nedenle günümüzde üreter orifisi dilatasyonuna çoğu olguda gerek duyulmamaktadır. 1990'l1 yıllarda üreter içinde hareketi zor olan tam rijit URS'lerin yerine daha yumuşak, esneyebilen ve işlemden sonra eski haline dönebilen semi-rijit URS'ler üretilmiştir.

Rijit üreteroskoplarla böbrek pelvisi ve kalikslerindeki taşlara ulaşmak her zaman mümkün değildir ve yüksek komplikasyon riskine sahiptir. İlerleyen teknoloji ile birlikte küçük çaplı, geniş görme alanlı ve yüksek görüntü kaliteli rijid ve fleksibl üreteroskoplar üretilmiştir. Yüksek hareket (defleksiyon) yeteneğine sahip ve göreceli olarak daha dayanıklı fleksibl üreteroskoplar sayesinde üst üriner sisteme ulaşmak da mümkün olmuştur. Yeni jenerasyon üreteroskoplarla üst üriner sistemin içi tamamı ile görüntülenebilmiş ve holmium lazer gibi etkin ve güvenilir litotriptörlerin de geliştirilmesi ile taş tedavisinde önemli bir alternatif haline gelmiştir (5).

Rijid üreteroskopların günümüzde kullanımı oldukça

Tablo 1: Piyasadaki semirijit URS'lerin karşılaştırılması.

\begin{tabular}{|c|c|c|c|c|c|c|}
\hline Firma İsmi & Model İsmi & $\begin{array}{l}\text { Uzunluk } \\
(\mathrm{cm})\end{array}$ & $\begin{array}{l}\text { Proksimal } \\
\text { Çap (Fr) }\end{array}$ & $\begin{array}{c}\text { Distal } \\
\text { Çap (Fr) }\end{array}$ & $\begin{array}{l}\text { Çalışma } \\
\text { Kanalı } \\
\text { Çapı (Fr) }\end{array}$ & Özellik \\
\hline Storz & $27000 \mathrm{~L} / \mathrm{K}$ & $34 / 43$ & 7 & 6.5 & 4.8 & İnce yapıdadır. Geniş çalışma kanalı \\
\hline Storz & $27001 \mathrm{~L} / \mathrm{K}$ & $34 / 43$ & 8 & 7 & 5 & Geniş çalışma kanalı \\
\hline Storz & $27002 \mathrm{~L} / \mathrm{K}$ & $34 / 43$ & 9.5 & 8 & 6 & Geniş çalışma kanalı \\
\hline Storz & 27003 L Michel & 43 & 9.5 & 9 & $3 / 3$ & $\begin{array}{l}\text { Enstrüman kanalının altında ek } \\
\text { irrigasyon kanalı var }\end{array}$ \\
\hline Gyrus ACMI & MR0-742A & 42 & 11.2 & 7.7 & 5.4 & Geniş çalışma kanalı \\
\hline Gyrus ACMI & MR-6/MR 6LA & $33 / 43$ & 10.2 & 6.9 & $3.4 / 2.3$ & Elastik üçgen şeklinde şaft \\
\hline Olympus & EndoEYE & 43 & 9.9 & 8.5 & 4.2 & $\begin{array}{l}\text { Video-üreteroskop olduğundan } \\
\text { yüksek görüntü kalitesi }\end{array}$ \\
\hline Wolf & D.O.C. & $33 / 43$ & 8.5 & 6.5 & $4.0 / 2.4$ & $\begin{array}{l}\text { İki adet büyük çalışma kanalı, oval } \\
\text { şekil }\end{array}$ \\
\hline Wolf & Ultrathin & $33 / 43$ & 6.5 & 4.5 & 4 & $\begin{array}{l}\text { Çok ince yapıda olmasına rağmen } \\
\text { geniş çalışma kanalı }\end{array}$ \\
\hline Wolf & Needle & $31.5 / 43$ & 6.5 & 4.5 & 3 & Çok ince yapıda \\
\hline
\end{tabular}


azalmıştır. Bunun yerini günümüzde daha ince yapıda ve çift çalışma kanalı olan semirijid üreteroskoplar almıştır. Semirijid üreteroskoplar dış çapları, çalışma kanalları, uzunlukları gibi etmenlerden dolayı çeşitlilik gösterebilmektedir. Birçok değişik firmaya ait, ince veya daha kalın çaplı, pediyatrik veya erişkin uyumlu üreteroskop çeşitleri mevcuttur (5). Ürolojide yaygın olarak kullanılan semi-rijit üreterorenoskopların farklı farklı özellikleri mevcuttur (Tablo 1).

\section{Fleksibl URS'lerde Teknolojik Gelişim}

İlk fleksibl URS 1960'larda geliştirildi. Ancak bu fleksibl URS'lerde tam bir defleksiyon sistemi ve çalışma kanalları mevcut değildi (6). Yeni fleksibl URS'lerin ve holmiyum lazerin kullanıma girdiği 1990'lara kadar fleksibl URS'ler yaygın olarak kullanılmamıştır $(7,8)$. Fleksibl URS'ler basit olarak fiberoptik görüntüleme sistemi, defleksiyon mekanizması, çalışma ve kanalından oluşur. Ancak son zamanlarda dijital görüntüleme sistemlerine sahip dijital fleksibl URS'ler üretilmiştir. Bu dijital cihazların uç kısmında görüntüyü alan bir çip bulunmaktadır. Görüntü kaliteleri fiberoptik kablolardan oluşan fleksibl URS'lerden oldukça iyidir. Ayrı bir ışık kablosu ve kamera başlığına ihtiyaç duymazlar. Bu nedenle daha hafiftirler ve uzun süre manuel olarak ameliyat yapan ürologlar için daha ergonomiktirler.

Fleksibl URS'lerde en önemli teknolojik gelişme fiberoptik sistemden dijital sisteme geçiştir (Resim 1A,B). Dijital URS'ler, fiberoptik URS'lerle karşılaştırıldığında görüntü kalitesi ve yakınlaştırma kapasitesini \%150 oranında artırmıştır (9). High Definition (HD) görüntüleme teknolojisi ile birlikte distal uç sensörlerinin (chip-on-the-tip) kullanılması yüksek çözünürlüklü görüntü elde edilmesini sağlamıştır. İki tür algılayıcı vardır: yük bağlı aygıt (CCD) ve tamamlayıcı metal oksit yarı iletken (CMOS). CCD ve CMOS görüntü sensörleri, görüntüleri dijital olarak yakalamak için kullanılan iki farklı teknolojidir. Bir CCD, küçük bir çipte yüzlerce bireysel resim öğesinden (piksel) oluşur. Her piksel, minik bir elektrik şarjı depolayarak üzerine düşen ışığa tepki verir. Pikseller, kameranın video işleme devresine sinyalleri taşıyan dikey ve yatay aktarım kayıtlarıyla hassas bir şekilde düzenlenir. Sinyallerin bu şekilde aktarılması $60 \mathrm{~Hz}$ 'de gerçekleşir. CMOS çipi dijital renkli görüntüler sağlayabilen minyatür bir cihazdır. CMOS çipi, CMOS yarı iletken prosesi kullanılarak üretilen bir çeşit aktif piksel algılayıcıdır. Her bir fotosensörün yanındaki ekstra devre, 1şık enerjisini voltaja çevirir. Voltajı dijital veriye dönüştürmek için çip üzerin- deki ilave devre de kullanılabilir. CMOS, potansiyel olarak daha az bileşenle uygulanabilir, daha az güç tüketebilir ve CCD'lerden daha hızlı okunabilir. CCD daha olgun bir teknolojidir ve çoğu bakımdan CMOS'e eşittir. CMOS sensörleri CCD sensörlerden daha ucuzdur (9). Uçtaki çip teknolojisi, endoskop tutacağı üzerinde bir kamera kafasına olan ihtiyacı ortadan kaldırır. Bu sayede endoskoplar yaklaşık \%50 oranında daha hafif hale gelmiştir ve bu durum da ameliyatı yapan üroloğun daha ergonomik olarak ameliyatı gerçekleştirmesini sağlamaktadır.

Light-emitting diode (LED)'ler, elektrik enerjisi ile yüklü bir malzemenin elektronik olarak uyarılmasından kaynaklanan, fotonların emisyonunun oluştuğu bir olay olan elektrolüminesansla çalışan yarı iletkenler olarak adlandırılırlar. Böylece elektrik yükü görünür ışığa aktarılır. LED'ler, gösterge lambaları, arka cam ve fren lambaları gibi otomobillerde ve son teknolojiye sahip endoskopik cihazlarda kullanılan birçok elektronik cihazda kullanılmaktadır. Dijital fleksibl URS'un ucu, harici bir ışık kaynağına duyulan gereksinimi ortadan kaldıran ve böylece cihaz veya hasta yanıkları riski taşımayan ikili LED ile çalışan hafif taşıyıcıları barındırır (10).

Narrow Band Imaging (NBI), 1şığın soğurma ve saçılma özelliklerini optimize ederek kılcal damarların, venlerin ve diğer ince doku yapılarının görünürlüğünü kökten geliştiren optik bir filtreleme teknolojisidir. NBI standart beyaz 1 şı̆̆ $415 \mathrm{~nm}$, mavi ve 540 nm'lik yeşil 1şıklık iki bant genişliğinde filtreler (11). Sonuç olarak, mukozal yüzeydeki kılcal damarlar bağ dokusu alt epitelyum katmanında kahverengi ve damarlar görünür ve epitelyal, subepitelyal doku ve damarlar arasındaki kontrastı arttırır. Bunun bir filtre olduğu göz önüne alındığında, güvenli, herhangi bir damlatma gerektirmemekte ve vizyon modalitesi herhangi bir sınırlama olmaksızın NBI'den beyaz ışı̆ga veya tersine çevrilebilir. Bu teknik, farklı kontrastlar kullanarak şüpheli kitleyi daha net görüntülememizi sağlar. Hatta görülmeyen şüpheli alanların tespit edilmesini sağlayabilir. NBI teknolojisi özellikle pelvikalisyel sistem içindeki şüpheli alanların biyopsileri veya lazer ablasyonu gibi tümör çalışmaları için kullanıldığında daha faydalıdır (9,11-14), (Resim 2).

Diğer bir görüntü kalitesini artıran yöntem ise son zamanlarda bir firma tarafından geliştirilen fleksibl URS' de kullanılan clara ve chroma modlarıdır. Clara, otomatik olarak bir görüntünün koyu görüntü alanlarını tanımlar ve aydınlatır. Böylece bazı anatomik alanlar diğerlerinden daha iyi aydınlatılır. Özellikle karanlık olan arka alanlar daha net
A

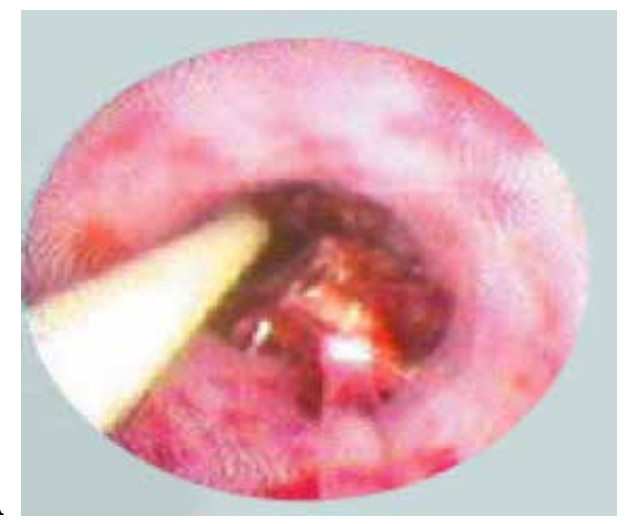

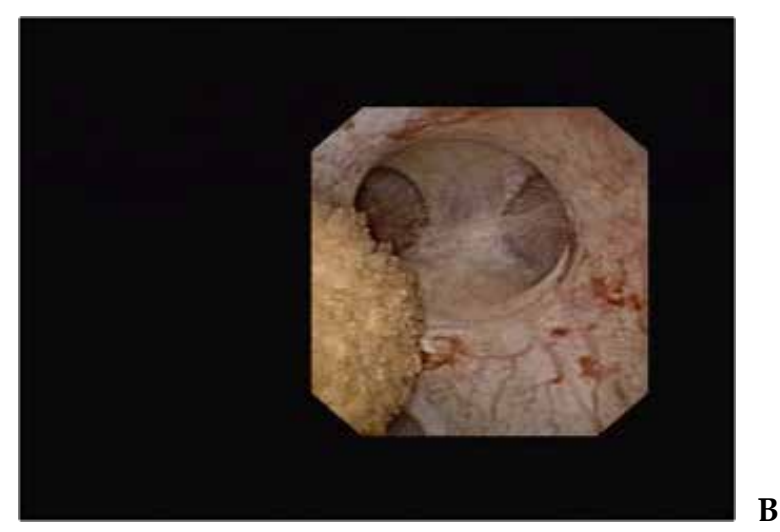

B

Resim 1: A. Fiberoptik fleksibl URS'de görüntü ile B. Dijital Fleksibl URS'deki görüntü 
A
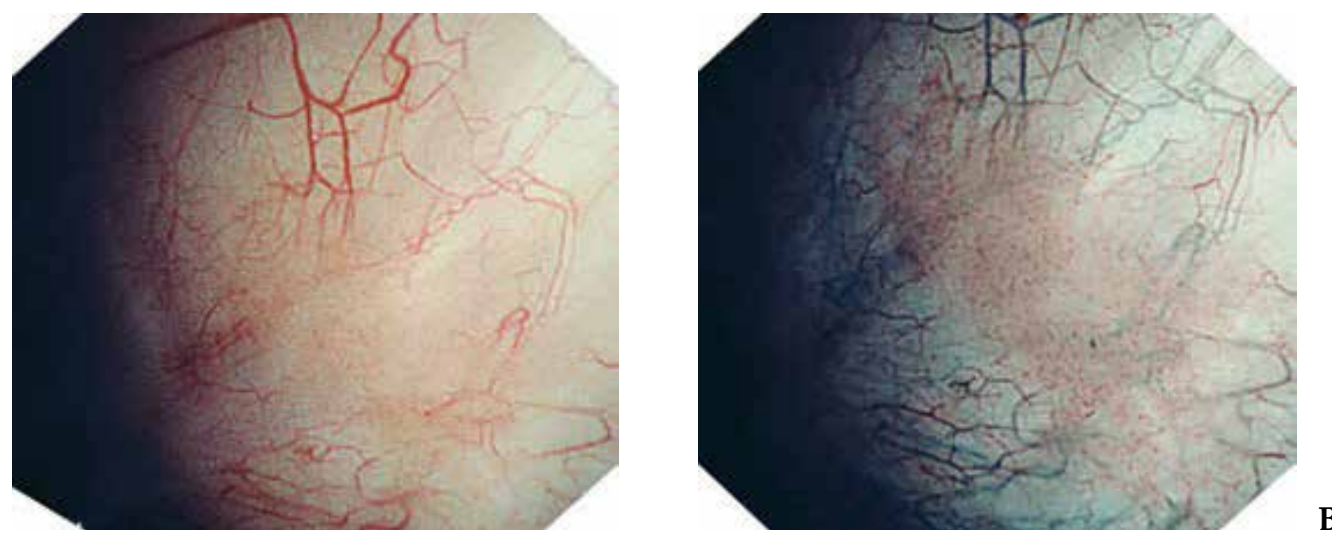

Resim 2: A. Normal beyaz ışık ve B. NBI arasındaki görüntü farkları (14)

aydınlatılarak taş kırılırken arka plandaki dokuyu lazerin yan etkilerinden koruma imkanı daha kolay olur. URS taşa yaklaştıkça bir parlama ortaya çıkar. İşte clara, aşırı parlama ve yansımaları önleyerek hem aydınlık ve hem de karanlık alanların net bir şekilde görünmesini sağlar. Sistem aynı zamanda cerrahların kan damarlarını daha iyi görselleştirmesini sağlamak için dokudaki video görüntüsünün kırmızı renk kontrastını arttıran chroma'yı da içermekte. Birçok cerrahi prosedür için, clara+chroma ayarı seçilerek, iki uygulama birleştirilir ve maksimum netlikte bir görüntü elde edilir (Resim 3).

Son olarak dijital teknoloji ile iki kanallı endoskop üretilmiştir. İki çalışma kanalı sayesinde irrigasyon akışı daha iyi olmakta bu da görüntünün daha kaliteli olmasını sağlamaktadir (15) (Tablo2).

\section{Floroskopisiz URS}

Üriner sistem taş hastalığının tedavisinde floroskopi yaygın olarak kullanılmaktadır. Buna bağlı olarak ortaya çıkan radyasyon ise hem hasta hem de tedaviyi gerçekleştiren ekip üzerinde istenmeyen etkiler oluşturmaktadır. Son zamanlarda skopi kullanmadan kilavuz tel üzerinden ilerletilen fleksibl URS ile ameliyatın tamamlanması alternatif olarak uygulanmaktadır $(16,17)$. Yine üreteral giriş kılıfı da radyasyon kullanmadan dikkatli bir şekilde yerleştirilebilir (18).

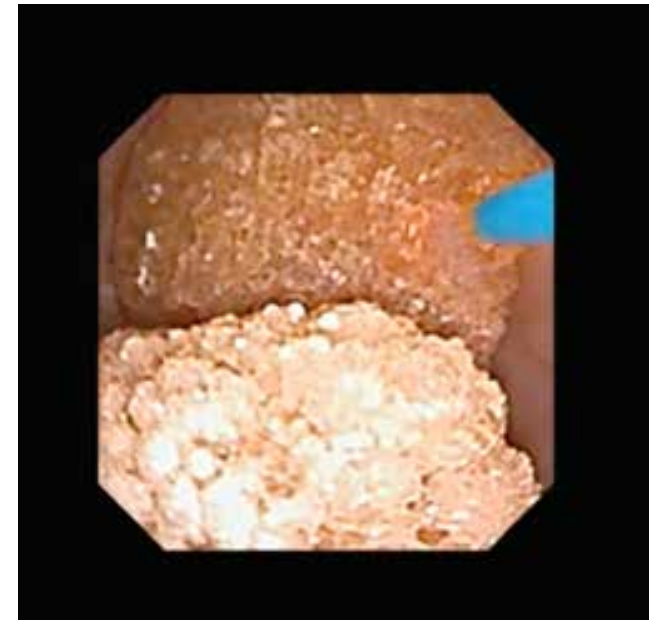

Resim 3: Clara ve Chroma modlarının kombine kullanılması sonrası ürik asit taşı olan bir hastadaki görüntü (4)

Floroskopisiz URS ameliyatları özellikle; çocuklarda, gebelerde ve sık tekrarlayan üriner taşı olan hastalarda önemlidir. Ameliyat sonrası üreteral stent konulacaksa fleksibl URS'nin üreteropelvik ve üreterovesikal arasındaki mesafesi işaretli

Tablo 2: Piyasadaki fleksibl URS’lerin karşılaştırılması.

\begin{tabular}{|c|c|c|c|c|c|c|}
\hline Firma İsmi & Model İsmi & $\begin{array}{l}\text { Görüntü } \\
\text { türüu }\end{array}$ & $\begin{array}{l}\text { Uç Çapı } \\
\text { (Fr) }\end{array}$ & $\begin{array}{l}\text { Defleksiyon } \\
\text { (Derece) }\end{array}$ & $\begin{array}{l}\text { Çalışma } \\
\text { Kanalı } \\
\text { Çapı (Fr) }\end{array}$ & Özellik \\
\hline Storz & Flex-X2 & Optik & 7.5 & $270 / 270$ & 3.6 & Fotodinamik diyagnoz \\
\hline Storz & Flex-Xc & Dijital & 8.5 & $270 / 270$ & 3.6 & \\
\hline Gyrus ACMI & DUR-8 Elite & Optik & 8.7 & $170 / 180$ & 3.6 & Sekonder defleksiyon \\
\hline Gyrus ACMI & DUR-D Invisio & Dijital & 8.7 & $250 / 250$ & 3.6 & $\begin{array}{l}\text { Objektif kafası çıkarılabilir } \\
\text { değiştirilebilir }\end{array}$ \\
\hline Olympus & DUR-8 Ultra & Optik & 8.6 & $270 / 270$ & 3.6 & \\
\hline Olympus & URF-P5 & Optik & 5.3 & $180 / 275$ & 3.6 & \\
\hline Olympus & URF-V & Dijital & 8.5 & $180 / 275$ & 3.6 & Narrow Band Imaging \\
\hline Wolf & Viper & Optik & 6.0 & $270 / 270$ & 3.6 & \\
\hline Wolf & Cobra & Optik & 6.0 & $270 / 270$ & $3.3 / 3.3$ & İki adet çalışma kanalı \\
\hline Wolf & Cobra Vision & Dijital & 6.3 & $270 / 270$ & $3.3 / 2.4$ & İki adet çalışma kanalı \\
\hline Wolf & Boa Vision & Dijital & 6.6 & $270 / 270$ & 3.6 & \\
\hline Stryker & Flexvision U500 & Optik & 6.9 & $275 / 275$ & 3.6 & \\
\hline
\end{tabular}


A
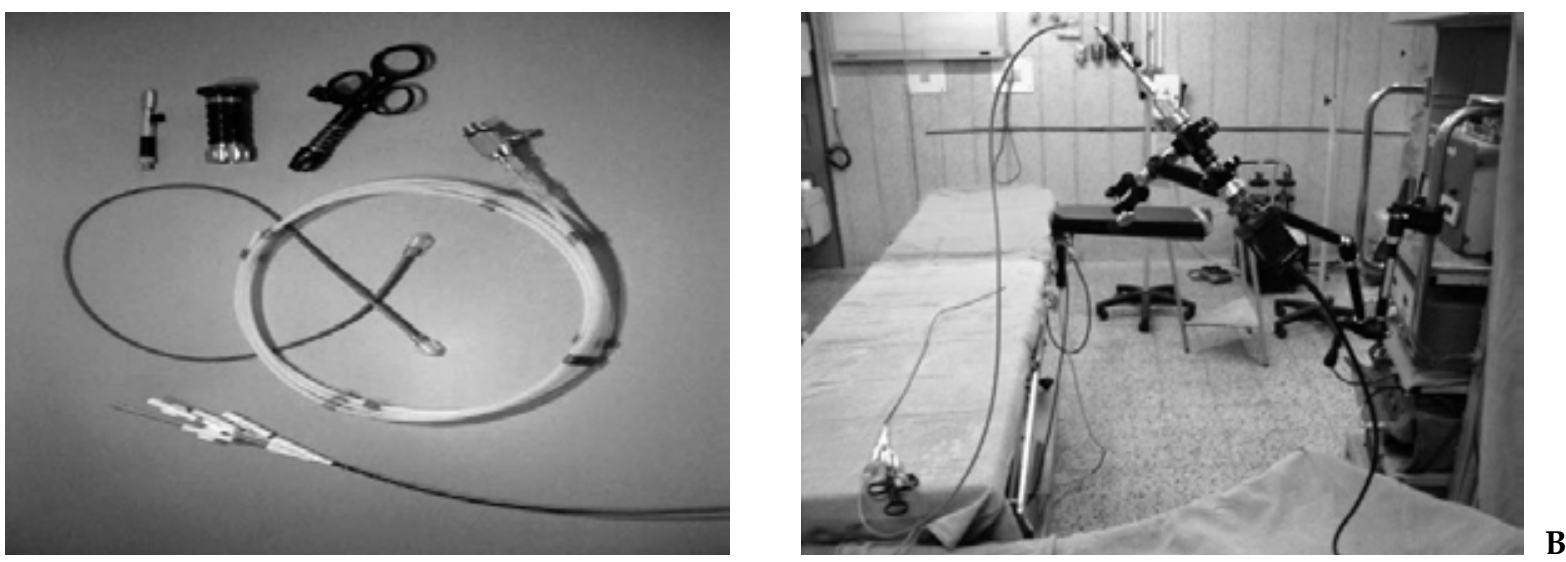

Resim 4: Polyscope. A. Polyscope'un parçaları. B. Polyscope'un hazırlanmış hali

noktalar arası ölçülerek tespit edilebilir yada direk endoskopik görüş altında kılavuz tel üzerinden stent ilerletilerek böbrek içinde durduğu noktada bırakılabilir. Görüş altında ilerletildiği için mesane içinde stentin distal ucunun durumu da görülerek stentin uygun şekilde yerleşmesi sağlanır.

\section{Tek Kullanımlık Fleksibl URS'ler}

Çok kullanımlık fleksibl URS'ler özellikle enfeksiyon gelişimi açısından risk taşımaktadır. Yine uzun süreli kullanımlarda alette fiziksel hasarlar ortaya çıkmakta, görüntü kalitesi bozulmaktadır. Özellikle eğitim kurumlarında yetersiz deneyimi olanlar tarafından kullanılması sonucu kısa sürede bozularak maliyet açısından sorunlar yaratmaktadır. Bu nedenlerle son zamanlarda tek kullanımlık fleksibl URS'ler üretilmiştir. İlk üretilen tek kullanımlık fleksibl üreteroskop Polyscope'dur (19). Bu cihaz, tekrar kullanilabilir bir optik kablo, bir ışık kablosu, çalışma kanalı ve bir kumanda mekanizması ile birlikte kanalları olan tek kullanımlık multilümen endoskopik bir kateterden oluşmaktadır (Resim 4). Polyscope ile yapılan ilk sonuçlar, cihazın teşhis ve terapötik URS için güvenli ve etkili olduğunu, üriner taşların $3 \mathrm{~cm}$ 'ye kadar olan kısmının tedavisi de dahil olmak üzere önerilebileceğini göstermektedir (19-22). Maliyeti düşürmek için tek kullanımlık fleksibl URS'lerin tekrar steril edilerek de kullanılabileceği bildirilmiştir (21). Ancak bu durumda tek kullanımlık fleksibl URS'lerin ortaya çıkmasındaki temel nedenlerden biri olan "enfeksiyon oranlarının azaltılması için tek kullanım" mantığından uzaklaşmış olunmaktadır. Bu cihazın en büyük dezavantajı ise tek yönlü sapmaya sahip olmasidir.

Tek kullanımlık üreteroskopların bir sonraki üretilen modeli SemiFlex'dir. Cihazın dış çapı $7.85 F^{\prime}$ dir. Cihaz 3.4F bir çalışma kılıfı ve irrigasyon için bir Y-port adaptörü içermektedir. SemiFlex'in en büyük farkı aktif yukarı ve aşağı defleksiyon özelliğinin bulunmasıdır. Ticari olarak satılan diğer altı çok kullanımlık fleksibl üreteroskop ile karşılaştırıldığında, SemiFlex'in benzer şekilde aktif uç defleksiyonu, sıvı akış hızı ve görüntü kalitesine sahip olduğu tespit edilmiştir (23).

Yine yakın zamanda Pusen isminde Avustralya'da üretilen tek kullanımlık fleksibl URS piyasaya sürülmüştür. Her iki yöne 270 derece defleksiyon yeteneği mevcuttur. 3.6 F çalışma kanalı mevcuttur. Kendine ait görüntü tele- vizyon sisteminin bulunması maliyeti biraz artırmaktadır. Kliniğimizde de denediğimiz bu sistemin görüntüsü diğer fiberoptik fleksibl URS'ler kadar iyi olarak değerlendirilmiştir. Vaka sayısı fazla olan yüksek volümlü merkezlerde tercih edilebilir.

Son zamanlarda tek kullanımlık dijital fleksibl URS üretildi (LithoVue) (Resim 5). Bu cihaz her iki yönde de 270 derece defleksiyon yapma özelliğine sahiptir. Yapılan taze kadavra çalışmasında LithoVue'nun, diğer konvansiyonel fiberoptik ve dijital fleksibl üreterorenoskoplarla karşılaştırıldığında görüntü kalitesi ve manevra kabiliyetleri bakımından diğerleri ile karşılaştırılabilir olduğu tespit edilmiştir (24). Daha sonra yapılan klinik çalışmalarda da hem LithoVue'nun maliyet bakımından daha ucuz olduğu tespit edilmiş hem de etkili olduğu ortaya konulmuştur $(25,26)$.

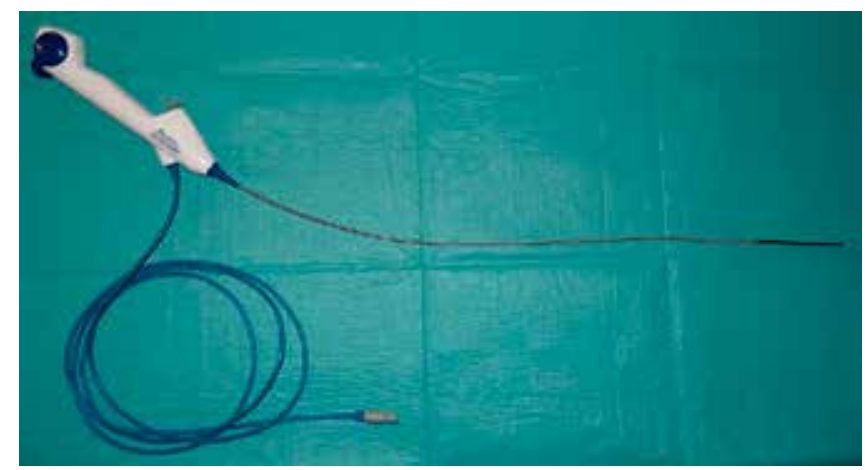

Resim 5: Tek kullanımlık dijital fleksibl URS (LithoVue) (25)

\section{Kombine Fleksibl Semirijit URS}

Semirijit URS ile fleksibl URS'yi birleştiren yeni bir cihaz geliştirilmiştir (Sun's tip flexible-semirigid ureterorenoscope). $\mathrm{Bu}$ cihaz $9 \mathrm{~cm}$ 'lik esnek fleksibl distal uç ve sert bir gövdeden oluşmaktadır (Resim 6). Fleksibl uç çıkarılarak sistem sadece semirijit URS olarak da kullanılabilir. Her iki yöne 250/270 derece defleksiyon yeteneğine sahiptir. Uç kısminda 8.2 F, proksimal kısımda ise $9.8 \mathrm{~F}$ çaptadır. Bu boyutlar piyasadaki son dönem fleksibl URS'lerin çoğundan büyük, semirijit URS'lerden ise küçüktür. Yapılan klinik çalışmada Gao ve 

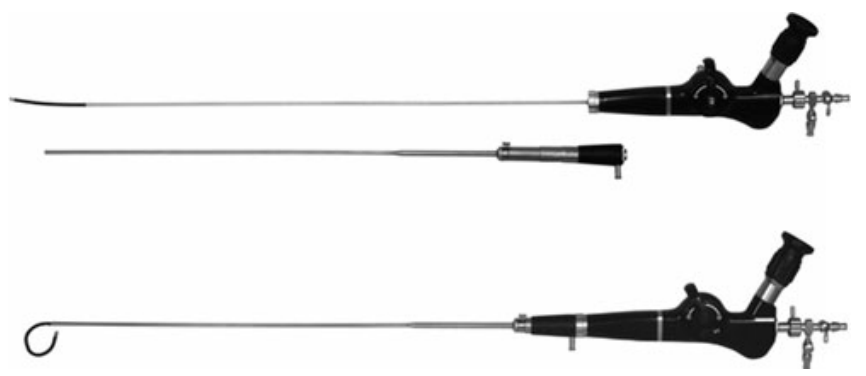

Resim 6: Sun's tip semirijit\&fleksibl URS (27)

arkadaşları, bu cihazın proksimal üreteral (135) ve renal (81) taşların tedavisi için etkinliğini ve güvenilirliğini test ettiler. Sadece üç hastada tedavi edilemeyen taşlar mevcuttu ve bunlar küçük açılara sahip alt kalikslerde bulunmaktaydı. Bu durum da konvansiyonel fleksibl URS'lerde olduğu gibi tedaviyi engelledi. Bu çalışmada, düşük derecede ve önemsiz komplikasyonlara rastlanmışır. Bu çalışmada genel başarı oranı yaklaşık \%92 olarak tespit edilmiştir (27). Daha fazla kontrollü çalışmalara ihtiyaç duyulsa da, erken sonuçlar, çok amaçlı cihazların teşvik edilmesi gerektiğini düşündürmektedir.

\section{Robot Yardımlı FleksibI URS}

Ürolojide robotik sistemlerin kullanılması son 5 senede hızlı bir artış göstermiştir (28). Cerrahi operasyonlarda robot teknolojisi ilk kez $1988^{\prime}$ de stereotaktik beyin cerrahi operasyonunda robotik kolun kullanılmasıyla başlamıştır. Robotik teknolojinin üroloji de ilk kullanımı ise modifiye edilen bu robotik kolun prostatın transüretral rezeksiyonu operasyonunda kullanilması olarak kabul edilmektedir $(29,30)$. Bu rijit sistemlerdeki robotik çalışmalar maalesef gelişme göstererek klinik kullanıma girememiştir. Bu dönem ses kontrollü bir robot kolunun hassas, duyarlı bir şekilde laparoskopi sirasinda kamerayı el kullanmadan sesli komutla hareket ettirmesiyle farklı bir boyuta taşınmıştır (Aesop, Computer Motion) (31). Bunu en gelişmiş robotik sistem olan masterslave sistemlerin geliştirilmesi izlemiştir (Zeus, Computer
Motion; da Vinci, Intuitive Surgical). Bu sistem, robot kolların bulunduğu robotik ünite ve cerrahın el hareketlerinin birebir taklit edilmesini sağlayan konsoldan oluşmaktadır. Günümüze kadar geliştirilmiş olan master-slave sistemler; Aesop, Zeus ve da Vinci olmakla birlikte bunlar içinde en sık kullanılan ve en fazla kabul görmüş olan robotik sistem da Vinci'dir (32). Her iki sistem (Zeus ve da Vinci) başlangıçta kardiyak cerrahi uygulamalar için tasarlanmış ve test edilmiş olmasına rağmen, da Vinci sisteminin günümüzde başlıca uygulamaları ürolojiktir (28).

Endoüroloji uzmanı, lazer fiberi veya basketleri yerleştirmek ve ilerletmek, endoskopu tutup hedefe odaklanırken irrigasyon başlatmak ve sürdürmek için yardıma ihtiyacı vardır. Uç kısmında çip barındıran yeni teknoloji dijital endoskoplar, klasik fiberoptik sistemlerle karşılaştırıldığında böbrek toplama sistemine oryante olmakta zorluklara neden olabilir (33). Fleksibl URS sırasında, cerrah floroskopi, laser litotripsi veya irrigasyon için çok sayıda ayak pedalıyla birkaç cihazı aktive etmek zorundadır. Çoğu ürolog bunu ayakta durarak yapar. Bu da ortopedik şikayetlerle sonuçlanabilecek optimal olmayan ergonomik bir duruşla yerine getirilir. Yine uzun süren ameliyatlarda fleksibl URS cihazını elde tutmak ve yapılan manüplasyonlar ellerde, kollarda ve parmaklarda bir takım sorunlara neden olabilir $(34,35)$. Özellikle uzun ameliyat süreleri gerektiren daha büyük taşların bulunması durumunda, cerrahın yorgunluğu ameliyat performansı üzerinde olumsuz bir etkide bulunabilir. Diğer fluoroskopi eşliğinde yapılan işlemler gibi, Fleksibl URS esnasında operatör ve cerrahi ekip, hastayla birlikte belirgin radyasyona maruz kalmaktadır (36-38). Bütün bu olumsuz etkileri ortadan kaldırmak ya da en aza indirmek için çeşitli çalışmalar yapılmıştır.

Illk olarak Desai ve arkadaşları, intrakardiyak olarak kullanılan Hensen cihazını modifiye ederek robot yardımlı fleksibl URS tekniğinin olabilirliğini test etmişlerdir $(39,40)$. Ancak bu sistem geliştirilememiştir. 2012 yılında ise Türkiye'de Türk mühendislerinin yardımıyla Avicenna (İbni Sina) isminde robotik fleksibl URS cihazı geliştirilmiştir (33). Bu cihaz sayesinde cerrah hastadan ve radyasyondan uzakta ayakta durmadan bu işlemi gerçekleştirmektedir (Resim 7).
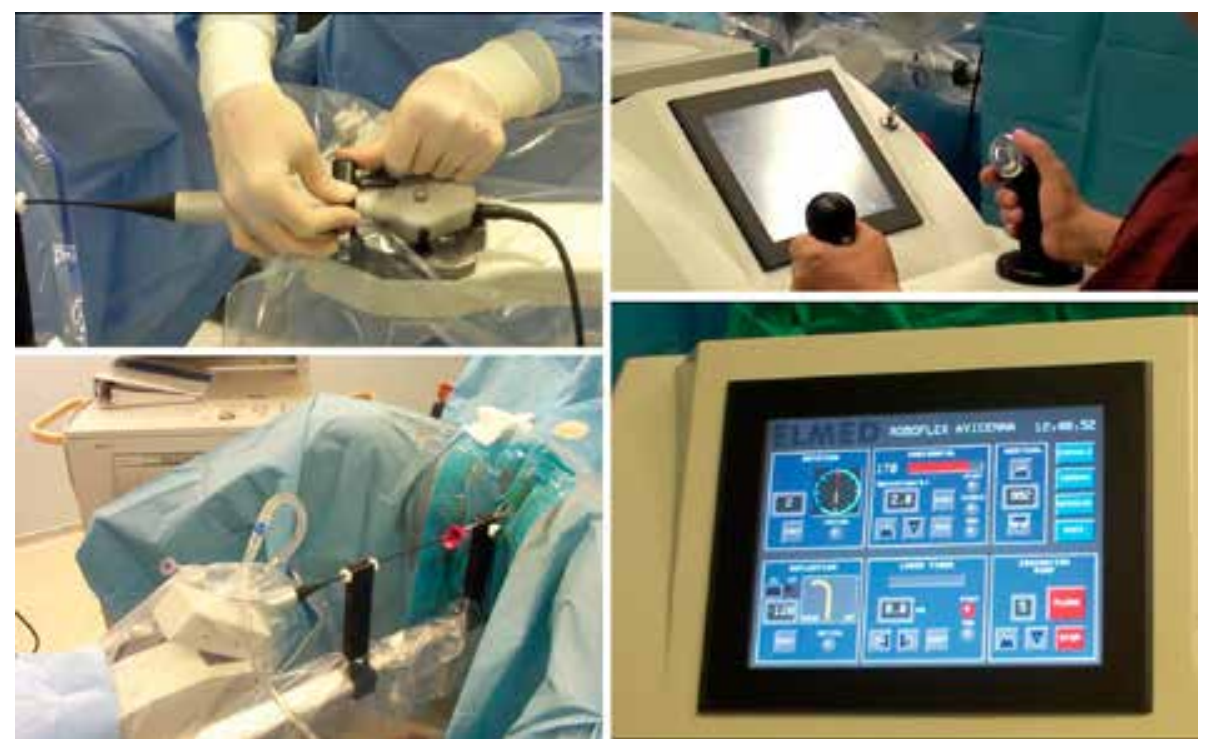

Resim 7: Robot Yardımlı Fleksibl URS (41) 
Elinde cihazları tutmadığ 1 ve ayakta durmadı $\breve{g}_{1}$ için daha rahat ortamda ameliyat yapabilmektedir. Ayrıca böbrek içindeki manipülasyonlar elle yapılmadığı için maksimum defleksiyon sağlanmaktadır. Çünkü zaman geçtikte cerrah yorulmakta ve böbrek içindeki hareketleri daha az hassasiyetle yapmaya başlamaktadır. Ayrıca bu sistem fleksibl URS cihazı ve lazer probu olmak üzere çeşitli cihaz enstrümanların da korunmasını, uzun süre kullanılmasını sağlamaktadır. Fleksibl URS cihazı robotik sistemin koruması altında olduğundan dışardan ve içerden hasarlanması daha zordur. Lazer probu sistem düz şekildeyken ilerletildiğinden cihazı delme ihtimali azalmaktadır. Yine lazer probu sıfır konumundayken sabitlendiğinden yanlışlıkla geri gelip atış sirasında optik sisteme zarar verme ihtimali yoktur. Robot konsülünde URS'nin pozisyonunu gösteren bölüm mecuttur. Konsül üzerinden lazer ve irrigasyon şiddeti ayarlanabilmekte, lazer probunun ileri geri hareketleri kontrol edilebilmektedir. Yine konsüldeki joystickler aracılığıyla fleksibl URS'nin sağa sola, ileri geri hareketleri ile defleksiyon hareketleri yapılabilmektedir (Resim 7). Ayrıca skopi çekilmesi ve lazerin aktive edilmesi ayakları kullanarak konsülden yapılmaktadır. Bu durum teknisyen ihtiyacını azaltmakla kalmamakta zaman kaybını da önlemektedir. Robotik sistem sayesinde uzun süre aynı pozisyonda sabit kalarak popcorn tekniğini kullanarak taşları çok küçük boyutlara ulaştırmak mümkün olmaktadır.

Yapılan erken dönem çalışmalarda Robotik fleksibl URS'nin oldukça ergonomik olduğu ve başarılı sonuçlar elde edildiği bildirilmiştir $(33,41,42)$. Biz de kliniğimizde toplam 11 hastada robotik fleksibl URS'yi deneme şansı bulduk (Resim 8). 2 vakada ek tedavi ihtiyacı duyuldu. Genel anlamda cerrah için ergonomik olduğu ve kolay öğrenme eğrisine sahip olduğu değerlendirildi.

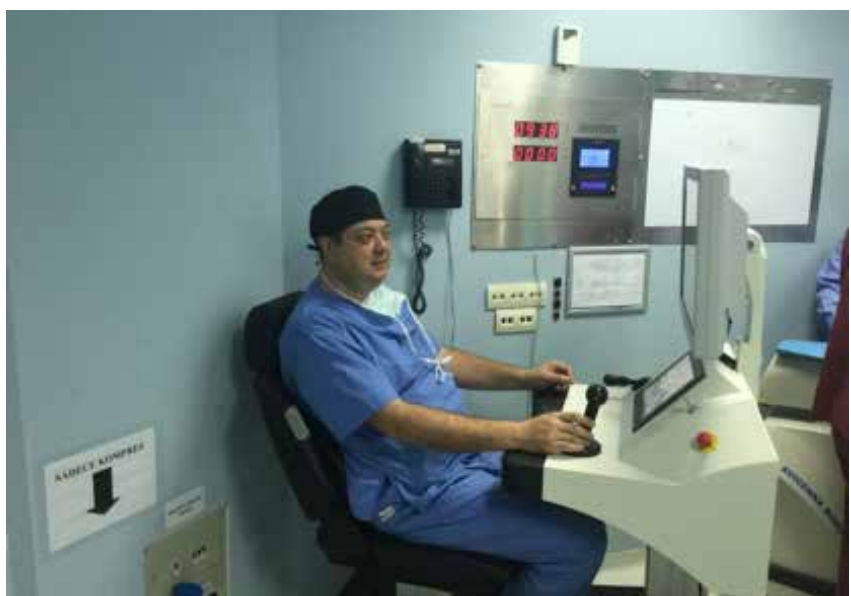

Resim 8: Kliniğimizde kullandığımız son versiyon Robotik Fleksibl URS

\section{Sonuç}

Son yıllarda özellikle üriner sistem taş hastalığı ve URS konusunda hızlı bir teknolojik gelişim olmuştur. Üreteroskopi için yeni fikirler, cihazlar ve yöntemler artarak devam etmektedir. Böylece çok sayıda yeni cihaz ve yöntem ürolojiye katılmaktadır. Biz ürologların bu teknolojik gelişmelere uzak kalmayarak güncel yöntemlere ayak uydurması gerekmektedir.

\section{Kaynaklar}

1. Rosa, M., et al., Recent finding and new technologies in nephrolitiasis: a review of the recent literature. BMC Urol, 2013. 13: p. 10.

2. Preminger, G.M., et al., Chapter 1: AUA guideline on management of staghorn calculi: diagnosis and treatment recommendations. J Urol, 2005. 173(6): p. 1991-2000.

3. Preminger, G.M., et al., 2007 Guideline for the management of ureteral calculi. Eur Urol, 2007. 52(6): p. 1610-31.

4. Antonelli, J.A., Innovations in surgical stone disease. Curr Opin Urol, 2016. 26(3): p. 240-7.

5. Reşorlu B , Ünsal A., Böbrek Taşlarının Tedavisinde Retrograd İntrarenal Cerrahi (RIRC). Turk Urol Sem, 2011. 2: p. 64-67.

6. Cho, S.Y., Current status of flexible ureteroscopy in urology. Korean J Urol, 2015. 56(10): p. 680-8.

7. Abdel-Razzak, O.M. and D.H. Bagley, Clinical experience with flexible ureteropyeloscopy. J Urol, 1992. 148(6): p. 1788-92.

8. Johnson, D.E., D.M. Cromeens, and R.E. Price, Use of the holmium:YAG laser in urology. Lasers Surg Med, 1992. 12(4): p. 353-63.

9. Papatsoris, A.G., et al., Novel technologies in flexible ureterorenoscopy. Arab J Urol, 2011. 9(1): p. 41-6.

10. Andonian, S., Z. Okeke, and A.D. Smith, Digital ureteroscopy: the next step. J Endourol, 2008. 22(4): p. 603-6.

11. Naselli, A. and P. Puppo, Narrow band imaging and bladder cancer: when and how. Urologia, 2015. 82 Suppl 2: p. S5-8.

12. Kutwin, P., et al., Photodynamic Diagnosis and NarrowBand Imaging in the Management of Bladder Cancer: A Review. Photomed Laser Surg, 2017.

13. Kobatake, K., et al., Advantage of transurethral resection with narrow band imaging for non-muscle invasive bladder cancer. Oncol Lett, 2015. 10(2): p. 1097-1102.

14. Bryan, R.T., L.J. Billingham, and D.M. Wallace, Narrowband imaging flexible cystoscopy in the detection of recurrent urothelial cancer of the bladder. BJU Int, 2008. 101(6): p. 702-5; discussion 705-6.

15. Bach, T., et al., Objective assessment of working tool impact on irrigation flow and visibility in flexible ureterorenoscopes. J Endourol, 2011. 25(7): p. 1125-9.

16. Greene, D.J., et al., Comparison of a reduced radiation fluoroscopy protocol to conventional fluoroscopy during uncomplicated ureteroscopy. Urology, 2011. 78(2): p. 286-90.

17. Olgin, G., et al., Ureteroscopy Without Fluoroscopy: A Feasibility Study and Comparison with Conventional Ureteroscopy. J Endourol, 2015. 29(6): p. 625-9.

18. Aboutaleb, H., Fluoroscopy free flexible ureteroscopy with holmium: Yttrium-aluminium-garnet laser lithotripsy for removal of renal calculi. Arab J Urol, 2016. 14(2): p. 123-30.

19. Bansal, H., et al., Polyscope: a new era in flexible ureterorenoscopy. J Endourol, 2011. 25(2): p. 317-21.

20. Yan, Z., et al., Modular flexible ureteroscopy and holmium laser lithotripsy for the treatment of renal and proximal ureteral calculi: A single-surgeon experience of 382 cases. Exp Ther Med, 2015. 10(4): p. 1467-1471. 
21. Johnson, M.T., T.A. Khemees, and B.E. Knudsen, Resilience of disposable endoscope optical fiber properties after repeat sterilization. J Endourol, 2013. 27(1): p. 71-4.

22. Ding, J., et al., Comparing the Efficacy of a Multimodular Flexible Ureteroscope With Its Conventional Counterpart in the Management of Renal Stones. Urology, 2015. 86(2): p. 224-9.

23. Boylu, U., et al., In vitro comparison of a disposable flexible ureteroscope and conventional flexible ureteroscopes. J Urol, 2009. 182(5): p. 2347-51.

24. Proietti, S., et al., Comparison of New Single-Use Digital Flexible Ureteroscope Versus Nondisposable Fiber Optic and Digital Ureteroscope in a Cadaveric Model. J Endourol, 2016. 30(6): p. 655-9.

25. Doizi, S., et al., First clinical evaluation of a new singleuse flexible ureteroscope (LithoVue ${ }^{\mathrm{TM}}$ ): a European prospective multicentric feasibility study. World J Urol, 2017. 35(5): p. 809-818.

26. Leveillee, R.J. and E.F. Kelly, Impressive Performance: New Disposable Digital Ureteroscope Allows for Extreme Lower Pole Access and Use of $365 \mu \mathrm{m}$ Holmium Laser Fiber. J Endourol Case Rep, 2016. 2(1): p. 114-6.

27. Gao, X., et al., A Novel Ureterorenoscope for the Management of Upper Urinary Tract Stones: Initial Experience from a Prospective Multicenter Study. J Endourol, 2015. 29(6): p. 718-24.

28. Aron, M., et al., Flexible robotics: a new paradigm. Curr Opin Urol, 2007. 17(3): p. 151-5.

29. Davies, B.L., et al., The development of a surgeon robot for prostatectomies. Proc Inst Mech Eng H, 1991. 205(1): p. 35-8.

30. Harris, S.J., et al., The Probot--an active robot for prostate resection. Proc Inst Mech Eng H, 1997. 211(4): p. 317-25.

31. Allaf, M.E., et al., Laparoscopic visual field. Voice vs foot pedal interfaces for control of the AESOP robot. Surg Endosc, 1998. 12(12): p. 1415-8.

32. Aytac O, T.H., Atug F, Lokalize Prostat Kanserinde Cerrahi Tedavinin Geleceği. Endoüroloji Bülteni, 2015. 8: p. $9-12$.
33. Saglam, R., et al., A new robot for flexible ureteroscopy: development and early clinical results (IDEAL stage 1-2b). Eur Urol, 2014. 66(6): p. 1092-100.

34. Elkoushy, M.A. and S. Andonian, Prevalence of orthopedic complaints among endourologists and their compliance with radiation safety measures. J Endourol, 2011. 25(10): p. 1609-13.

35. Healy, K.A., et al., Hand problems among endourologists. J Endourol, 2011. 25(12): p. 1915-20.

36. Cabrera, F., et al., Comparison of radiation exposure from fixed table fluoroscopy to a portable C-Arm during ureteroscopy. J Endourol, 2017.

37. Chen, T.T., et al., Radiation Exposure during the Evaluation and Management of Nephrolithiasis. J Urol, 2015. 194(4): p. 878-85.

38. Hellawell, G.O., et al., Radiation exposure and the urologist: what are the risks? J Urol, 2005. 174(3): p. 94852; discussion 952.

39. Desai, M.M., et al., Flexible robotic retrograde renoscopy: description of novel robotic device and preliminary laboratory experience. Urology, 2008. 72(1): p. 42-6.

40. Desai, M.M., et al., Robotic flexible ureteroscopy for renal calculi: initial clinical experience. J Urol, 2011. 186(2): p. 563-8.

41. Rassweiler, J., M.C. Rassweiler, and J. Klein, New technology in ureteroscopy and percutaneous nephrolithotomy. Curr Opin Urol, 2016. 26(1): p. 95-106.

42. Geavlete, P., et al., Robotic Flexible Ureteroscopy Versus Classic Flexible Ureteroscopy in Renal Stones: the Initial Romanian Experience. Chirurgia (Bucur), 2016. 111(4): p. 326-9.

Yazışma Adresi:

Selahattin Bedir,

Sağlık Bilimleri Üniversitesi, Gülhane Tıp Fakültesi, Üroloji

Anabilim Dal, Ankara

Tel: +90 5325991949

e-mail:drsselahattin@gmail.com 